\title{
It is not just the driveline
}

\author{
Ashish S. Shah, MD
}

From the Department of Cardiac Surgery, Vanderbilt University Medical Center, Nashville, Tenn.

Disclosures: Author has nothing to disclose with regard to commercial support.

Received for publication Aug 22, 2017; accepted for publication Aug 28, 2017; available ahead of print Sept 22, 2017.

Address for reprints: Ashish S. Shah, MD, Department of Cardiology, Vanderbilt Medical Center E, 121521 st Ave

S, Ste 5025, Nashville, TN 37232 (E-mail: ashish.s.shah@vanderbilt.edu).

J Thorac Cardiovasc Surg 2018;155:e39

$0022-5223 / \$ 36.00$

Copyright (C) 2017 by The American Association for Thoracic Surgery

http://dx.doi.org/10.1016/j.jtcvs.2017.08.097

Left ventricular assist devices are among the great human achievements of the 20th century. Rivaling heart transplantation, the number of technical challenges both seen and unforeseen have been significant. But item by item, surgeons and engineers have found solutions. There are persistent problems with biocompatibility, external power sources, and more difficult problems of long-standing univentricular support. The current case report ${ }^{1}$ is a reminder that basics of pump design and unimpeded outflow are important. Forever.

Understandably, our initial focus in the field was bleeding, right ventricular function, and just getting out of the hospital. As patients lived longer on device support, the attention shifted to chronic driveline infections and the limitation of externalized power sources. Now our plenary sessions are concentrating on gastrointestinal bleeding, pump thrombosis, and chronic right ventricular failure.

Now this. The authors ${ }^{1}$ make a compelling argument that the device was implanted correctly and the outflow graft was not twisted at the time of implant. Moreover, the device functioned well for a long time. And then it did not. Moreover, it is unclear how it happened.

Despite the promise of a manufactured solution to a huge public health problem, left ventricular assist devices will

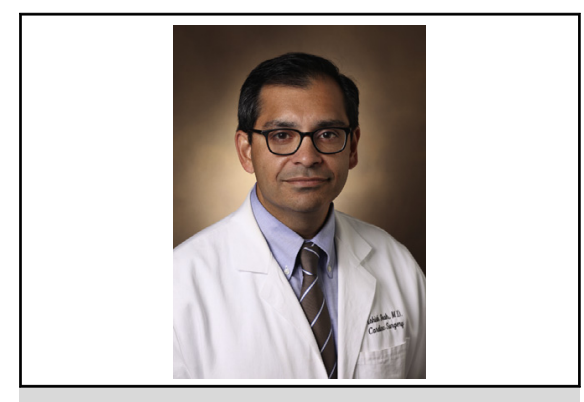

Ashish S. Shah, MD

Central Message

Despite significant improvements in pump design that have focused biocompatible surfaces, the present case report is a reminder that even the most sophisticated designs may fail under physiologic conditions.

See Article page e33.

continue to have a limited role in the treatment of heart failure patients. As this case report illustrates, ${ }^{1}$ there is a dynamic relationship between these devices and their human hosts. All the parts have to work. Forever.

\section{Reference}

1. Grüger T, Kaufmann F, Dreysse S, Falk V, Krabatsch T, Potapov E. Late postpump blood flow obstruction in the HeartMate 3 left ventricular assist device: The unusual case of a twisted outflow graft. J Thorac Cardiovasc Surg. 2018; 155:e33-5. 